\title{
DG-RAR for the treatment of symptomatic grade III and grade IV haemorrhoids: a 12-month multi-centre, prospective observational study
}

\author{
S. Roka, D. Gold, P. Walega, S. Lancee, E. Zagriadsky, A. Testa, A. N . Kukreja, A. Salat
}

Received: 21 August 2012 / Accepted: 31 October 2012 / Published online: 9 February 2013

(c) The Author(s) 2012. This article is published with open access at Springerlink.com

\section{Summary \\ Background Ultrasound-guided techniques represent a new treatment option in the treatment of haemor-}

The data have been presented in part at the Annual Meeting of the German Coloproctological Society in 2011.

Authors have contributed either to the conception and design of the study (S. Roka, D. Gold, S. Lancee, A. Salat), the acquisition of data (all authors) or the analysis and interpretation of data (S. Roka, D. Gold, A. Salat). This article was drafted by S. Roka and A. Salat. All authors have revised this article critically and gave the final approval of the version to be published.

S. Roka, MD $(\bowtie) \cdot$ A. Salat, MD

Department of Surgery, Medical University of Vienna, Währinger Gürtel 18-20, 1090 Vienna, Austria

e-mail: sebastian.roka@meduniwien.ac.at

D. Gold, MD

Professorial Department of Surgery, St Vincents Clinical School, University of New South Wales, Sydney, Australia

D. Gold, MD

Department of Surgery, North Hampshire Hospital, Basingstoke, England

P. Walega, MD

3rd Department of Surgery, Collegium Medicum, Jagiellonian University, Pradnicka Str. 37, 31-202 Krakow, Poland

S. Lancee, MD

Department of Surgery, Landeskrankenhaus Bludenz, Spitalgasse 13, 6700 Bludenz, Austria

E. Zagriadsky, MD

Medical Coloproctology Center, Bolshaya Molchanovka Street, Building 32, 121069 Moscow, Russia

A. Testa, MD

Department of Surgery, General Surgery Unit, Ospedale San Pietro Fatebenefratelli, Via Cassia 600, 00189 Rome, Italy

A. N. Kukreja, MD

Ratandeep Surgical Hospital and Endoscopy Clinic,

Nakshatra 2nd Floor, Ganesh Gali, Maninagar Cross Roads,

380008 Ahmedabad, Gujarat, India rhoids. Doppler-guided haemorrhoidal artery ligation (DG-HAL) proved efficacious in early haemorrhoidal disease, but lacks efficacy for stages III/IV. For these patients, haemorrhoidal artery ligation (HAL) has been combined with a running suture to reduce prolapsing haemorrhoidal tissue (recto-anal repair (RAR)).

Methods A prospective observational study was conducted in 184 patients with grade III $(58 \%)$ or grade IV (42\%) haemorrhoids in seven coloproctological centres. Primary endpoints were the recurrence of symptoms and need of further treatment (medical or surgical).

Results Post-operative complications were seen in $8 \%$ of patients. After a follow-up of 3 months, $91 \%$ of patients were free of symptoms and $91 \%$ of patients were satisfied with the result. After a follow-up of 12 months, $89 \%$ of patients were free of symptoms and $88 \%$ were satisfied with the result. Nineteen per cent of patients received further medical or surgical treatment.

Conclusions Doppler-guided recto-anal repair (DGRAR) proves to be an effective treatment option for the treatment of advanced haemorrhoidal disease that shows equal results to other established treatment options.

Keywords: Haemorrhoids, Haemorrhoidal artery ligation, Recto-anal repair

\section{Introduction}

A variety of treatment options are available for haemorrhoidal disease. Whereas early stages of the disease can usually be treated conservatively with success, advanced stages require a surgical approach. At present, surgical treatment generally involves resection of the haemorrhoidal cushions, as in conventional haemorrhoidectomy $(\mathrm{CH})$ or prolapse reduction as in stapled haemorrhoidopexy (SH) [1]. Despite excellent long-term 
results, $\mathrm{CH}$ is associated with significant side effects and complications. In addition to excessive post-operative pain, symptoms of incontinence and anal stenosis have been described in considerable numbers [2-5]. For SH, results are more convenient concerning post-operative pain. However, reoperations have been reported in up to $10 \%$ of patients $[5,6]$ and, albeit very rare, this technique can be associated with severe septic complications $[5,7]$.

Minimally invasive treatment options have become popular over the last few decades, even in coloproctology. Doppler-guided haemorrhoidal artery ligation (DG-HAL) was first described in 1995 by Morinaga et al. [8]. The principle of the technique was to ligate the proximal submucosal haemorrhoidal arteries, thereby reducing the blood flow to the haemorrhoidal cushions and eventually leading to fibrosis and shrinking of the haemorrhoids. Haemorrhoidal artery ligation (HAL) has since been analysed in several studies, which show excellent results for grade II and III haemorrhoidal disease. However, while HAL appears to control pain, bleeding, pruritus and mucous discharge with success, control of the prolapse seems to be more difficult in patients suffering from grade III or grade IV haemorrhoids. Persistent or recurrent prolapse in grade III disease has been described with rates of 6 [9], 9 [10] and $14 \%$ [11]. In studies involving patients with grade IV disease, even higher recurrence rates (RRs) such as 24 [10], 59 [11] and $67 \%$ [9] have been observed.

For these patients, in particular those suffering from grade IV haemorrhoids, reduction of inflow alone seems insufficient to reduce the haemorrhoidal cushions. Recto-anal repair (RAR), a technique developed and described by Scheyer [12], addresses this problem by supplementing HAL with a further step, whereby the haemorrhoidal tissue is gathered up and lifted back into position. Based on this principle of tissue reduction, RAR is an alternative to surgical removal that is made possible by placing a longitudinal running suture while using a specially designed proctoscope.

The aim of this prospective observational study for grade III and IV haemorrhoidal disease was to review several technical aspects and analyze 1-year results of this new method (DG-HAL/RAR) in terms of recurrence of prolapse and symptoms other than prolapse.

\section{Patients and methods}

This study was designed as a prospective observational study and was approved by the institutional review board. Included in the study were patients between the age of 18 and 80 years with symptomatic grade III and IV haemorrhoidal disease (according to Goligher classification), who had given their informed consent. Patients with a history of prior anal surgery and those considered unfit for surgery were excluded. Pregnant women and those in the puerperium were also excluded. Prior to surgery, all patients underwent a detailed examination for symptoms of haemorrhoidal disease. A standardised form was used to collect data from each patient during the study period.

Between March 2007 and December 2007, a total of 184 patients entered the study in seven proctological institutions. The centres contributed a median number of 21 patients (range 5-83). Patients were not required to enter the study in a consecutive order and the total number of patients screened was not documented. Of those 184 patients, 124 were male $(65 \%)$ and 64 female (35\%). The median age was 46.8 years (range $23-76$ ). The number of patients suffering from grade III haemorrhoids was 107 (58\%), while 77 patients (42\%) were classified to suffer from grade IV haemorrhoids. Pain was reported by 136 patients ( $74 \%$ ), itching by 139 (76 \%) and bleeding by $174(95 \%)$.

The surgical procedure was performed using the DGRAR proctoscope (A.M.I. Agency for Medical Innovations $\mathrm{GmbH}$ ) according to the manufacturer's guidelines. The proctoscope consists of an outer and inner tube. In the closed position, there is a lateral opening proximal to the ultrasound probe that allows detection and ligation of the feeding vessels (haemorrhoidal artery ligation). Rotating the outer tube of the proctoscope gradually opens a lateral slit to enable placement of a running suture, which serves to reduce the anal cushions and secure them back in their anatomical position (prolapse reduction). There were no recommendations for pain management. Postoperative pain was assessed using a visual analogue scale (VAS). Follow-up with a physical examination and questioning for recurrence of symptoms and satisfaction was performed 3 and 12 months after surgery by the treating physician.

Statistical analysis was performed using SPSS V 18.0.0. Median and mean were used for descriptive purposes. A linear regression analysis was performed to test influence of certain variables on recurrence of prolapse, recurrence of symptoms and patient satisfaction. A $p$-value of $<0.05$ was considered significant.

\section{Results}

\section{Surgical procedure}

A median of six (2-11) ligations and three (range 1-9) prolapse-reduction sutures (PRSs) were performed, whereby $80 \%$ of patients had six or more ligations, and $80 \%$ of patients had three or more PRSs. Surgery was performed under general anaesthesia in 132 patients (72\%), spinal anaesthesia in $45(25 \%)$ and local anaesthesia in $7(4 \%)$. The mean operating time was $35 \mathrm{~min}$ (range 13-75). Instances of significant bleeding during the procedure were observed in three patients $(2 \%)$. Post-operative complications were seen in 14 patients $(8 \%)$. Among them, 2 patients (1\%) suffered from bleeding which required operative revision, 11 patients $(7 \%)$ had perianal thromboses and 1 patient (1\%) was diagnosed with unspecified proctitis. The mean duration of the hospital stay was 2.3 days (range 1-9). 


Table 1. Burden of post-operative pain as measured by vi-
sual analogue scale (VAS 1-10)
\begin{tabular}{lcclc}
\hline $\begin{array}{l}\text { Time } \\
\text { (day) }\end{array}$ & VAS $\leq 3 n(\%)$ & VAS 4-6 $n(\%)$ & VAS $\geq 7 n(\%)$ & Total $n$ \\
\hline 1 & $115(74.2)$ & $34(21.9)$ & $6(3.9)$ & 155 \\
2 & $102(79.8)$ & $22(17.2)$ & $4(3.1)$ & 128 \\
3 & $95(84.8)$ & $12(10.7)$ & $5(4.5)$ & 112 \\
4 & $93(85.3)$ & $15(13.7)$ & $1(0.9)$ & 109 \\
\hline
\end{tabular}

\begin{tabular}{|c|c|c|c|}
\hline & $\begin{array}{l}\text { Before surgery } \\
(n=184 ; \%)\end{array}$ & $\begin{array}{l}3 \text { months } \\
(n=184 ; \%)\end{array}$ & $\begin{array}{l}12 \text { months } \\
(n=167 ; \%)\end{array}$ \\
\hline Pain & 136 (73.9) & $14(7.6)$ & $10(4.8)$ \\
\hline Itching & $139(75.5)$ & $19(10.3)$ & $9(4.2)$ \\
\hline Bleeding & $174(94.6)$ & $11(5.9)$ & $13(6.6)$ \\
\hline Patient satisfaction & & $168(91.3)$ & $148(87.6)$ \\
\hline Prolapse & $184(100)$ & $12(6.5)$ & $21(11.4)$ \\
\hline $\begin{array}{l}\text { Symptom and } \\
\text { prolapse free }\end{array}$ & & $162(88)$ & $141(84.4)$ \\
\hline Symptom free & & $167(90.8)$ & $152(89.4)$ \\
\hline Further treatment & & $28(15.2)$ & $32(18.9)$ \\
\hline
\end{tabular}

\section{Post-operative pain}

In the immediate post-operative period, i.e. prior to discharge from hospital, $20 \%$ of the patients reported pain higher than VAS 4 . This gradually diminished by day 4 , where only $3 \%$ of patients reported pain higher than VAS 4. Thirteen patients $(7 \%)$ reported pain higher than VAS 7 immediately after surgery. This gradually decreased to $1 \%$ at day 4 . There was only one patient with persistent pain for more than 4 days, post-operatively (Table 1).

\section{Recurrence of symptoms}

Three months follow-up was completed for all 184 patients (Table 2). Pain was still present in 14 patients (8\%), itching in $19(10 \%)$ and bleeding in $11(6 \%)$. Twelve patients (7\%) experienced persistent or recurrent prolapse. One hundred and sixty-seven patients (91\%) were free of symptoms and 168 patients (91 \%) were over-

\begin{tabular}{|c|c|c|c|c|}
\hline & \multicolumn{2}{|l|}{3 months } & \multicolumn{2}{|l|}{12 months } \\
\hline & $\begin{array}{l}\text { Grade III } \\
(n=107 ; \%)\end{array}$ & $\begin{array}{l}\text { Grade IV } \\
(n=77 ; \%)\end{array}$ & $\begin{array}{l}\text { Grade III } \\
(n=99 ; \%)\end{array}$ & $\begin{array}{l}\text { Grade IV } \\
(n=70 ; \%)\end{array}$ \\
\hline $\begin{array}{l}\text { Recurrence } \\
\text { of prolapse }\end{array}$ & $6(6)$ & $6(8)$ & $8(8)$ & $13(18)$ \\
\hline Pain & $5(5)$ & $9(12)$ & $3(3)$ & $7(10)$ \\
\hline Itching & $9(8)$ & $10(13)$ & 2 (2) & 7 (10) \\
\hline Bleeding & $3(3)$ & $8(10)$ & 2 (2) & $8(11)$ \\
\hline $\begin{array}{l}\text { Patient } \\
\text { satisfaction }\end{array}$ & 88.8 & 94.7 & 87.0 & 88.4 \\
\hline
\end{tabular}

all satisfied with the result of the procedure. Of these patients, $28(15 \%)$ received further treatment including $\mathrm{CH}$ (1 patient, $1 \%$ ), excision of skin tags (12 patients, $7 \%$ ), sclerotherapy (5 patients, $3 \%$ ) and treatment with an ointment, undefined and by surgeon preference (10 patients, $5 \%$ ).

At 12 month, follow-up was completed for 167 patients (92\%). Pain was still present in 10 of these patients (5\%), itching in 9 (4\%) and bleeding in 13 (7\%). Persistent or recurrent prolapse was experienced by 21 patients (11\%). One hundred and fifty-two patients (89\%) were free of symptoms and 148 patients $(88 \%)$ were satisfied with the result of the procedure. Thirty-two patients received one or more further treatments $(19 \%)$. These included $\mathrm{CH}(n=2)$, excision of skin tags $(n=12)$, sclerotherapy $(n=5)$, rubber band ligation $(n=4)$ and treatment with an ointment, undefined and by surgeon preference $(n=13)$.

\section{Factors influencing outcome}

Grade of disease, sex, age and the number of ligations and PRSs were tested for their respective influence on the recurrence of prolapse or symptoms, and patient satisfaction. With respect to recurrence of prolapse, there was a significant difference between patients with grade III and IV disease (Tables 3 and 4). The number of PRSs, and in particular the number of ligations, were shown to have significant influence on the recurrence of symptoms. With respect to symptom recurrence, optimal results were obtained with five to seven ligations (median 6) and three to four PRSs (median 4). The only factor correlating

\begin{tabular}{|c|c|c|c|c|c|c|}
\hline & \multicolumn{2}{|c|}{ Recurrence of prolapse } & \multicolumn{2}{|c|}{ Recurrence of symptoms } & \multicolumn{2}{|l|}{ Patient satisfaction } \\
\hline & RR (range) & $p$ & RR (range) & $p$ & RR (range) & $p$ \\
\hline Ligations & $-0.04(-0.83$ to 0.16$)$ & 0.18 & $-0.12(-0.17$ to -0.07$)$ & 0.0001 & 0.115 (0.06 to 0.17$)$ & 0.0001 \\
\hline Grade & 0.14 (0.03 to 0.2$)$ & 0.01 & $0.63(-0.38$ to 0.16$)$ & 0.221 & $-0.22(-0.13$ to 0.09$)$ & 0.69 \\
\hline Sex & $-0.07(-0.17$ to 0.03$)$ & 0.17 & $-0.93(-0.19$ to 0.01$)$ & 0.053 & $-0.19(-0.7$ to 0.32$)$ & 0.46 \\
\hline Age & 0.004 (0.0 to 0.01$)$ & 0.057 & $0.002(-0.003$ to 0.00$)$ & 0.474 & $0.02(-0.87$ to 0.12$)$ & 0.77 \\
\hline PRS & $0.3(-0.17$ to 0.08$)$ & 0.2 & 0.052 (0.006 to 0.09$)$ & 0.028 & $0.0(-0.01$ to 0.04$)$ & 0.91 \\
\hline
\end{tabular}


significantly with patient satisfaction was the number of ligations.

\section{Complications}

One patient ( $1 \%$ ) had anal stenosis-requiring dilation. One patient ( $1 \%$ ) suffered from urinary retention. Although considerable time had elapsed between the procedure and the onset of urinary retention, no other cause could be found. One patient ( $1 \%$ ) reported mild faecal incontinence 7 months after the procedure.

\section{Discussion}

While a variety of treatment options is available for grade I and II haemorrhoids, only SH and $\mathrm{CH}$ are considered to be a standard treatment for grade III disease, and just $\mathrm{CH}$ in the case of grade IV. In a meta-analysis [13], the RR for prolapse following $\mathrm{CH}$ is reported to be $4 \%$. However, both treatment options can be associated with extensive post-operative pain [5], faecal incontinence and anal stenosis [3]. Nonetheless, for most authors $\mathrm{CH}$ remains the standard treatment for advanced piles, because novel techniques including $\mathrm{SH}$ do not show the same effectiveness.

Although initial results from single centres have been promising [10, 12, 14-17], DG-HAL/RAR has not yet been adequately evaluated for grade III and IV haemorrhoids. The present study is the first international, multi-centre observational trial on the safety and effectiveness of DGHAL/RAR. We observed no major intra- or post-operative complications. The overall complication rate was $8 \%$. In terms of prolapse recurrence, results achieved by $\mathrm{CH}$ at 12 months are slightly better than those recorded during our trial [2]. In terms of control of other symptom, results from our series of high-grade HAL/RAR patients were superior to those published for $\mathrm{CH}$ und $\mathrm{SH}$ [2].

Most studies for grade III and IV haemorrhoids focus on the recurrence of prolapse, although prolapse may not be the leading symptom in a significant number of patients. We believe that control of symptoms other than prolapse and patient satisfaction is more relevant in evaluating efficacy. In terms of pain, pruritus or bleeding, almost nine out of ten patients were treated successfully and satisfied after a follow-up of 12 months.

In most cases, the variation was due to the persistence or development (as a result of shrinkage of haemorrhoidal tissue) of skin tags, which subsequently required further treatment. This problem is also prevalent among patients having undergone $\mathrm{CH}$ and $\mathrm{SH}$. In our series, $7 \%$ of patients required rubber band ligation, sclerotherapy or haemorrhoidectomy within 12 months of undergoing DG-HAL/RAR and $8 \%$ of patients received unspecified topical ointments, which we consider to be a low number. Taking all the above factors into account, we consider that our study demonstrates DG-HAL/RAR to be a safe and effective technique for grade III and IV haemorrhoids.

Furthermore, our study showed a low degree of postoperative pain. However, it should be noted that this study was not designed to assess post-operative pain for DG-HAL/RAR and, as such, pain assessment was only performed during the patient's hospital stay. The greatest extent of pain was experienced immediately post-operatively, and the most frequent cause of pain was perianal thrombosis. As the median hospital stay was only 2 days and patients without post-operative pain would have been discharged early, the number of patients with higher pain levels may be over-represented. Despite this technicality, post-operative pain would appear to be quite low. It should be mentioned that some centres performed the DG-HAL/RAR as a day-case procedure, but others require an overnight stay due to reimbursement considerations. This may have more impact on the length of stay than pain alone.

For the first time in a study concerning DG-HAL/RAR, a multi-variate analysis was carried out to demonstrate the statistically significant influence of various factors on parameters of efficacy. The number of PRSs and in particular the number of ligations were shown to influence the recurrence of symptoms, whereas the only factor affecting the recurrence of prolapse was the grade of disease. It is interesting to note that the only factor significantly influencing patient satisfaction was the number of ligations. Our data show a trend towards five to seven ligations and three to four PRSs; however, as the number of PRSs and ligations depended on each patient's vascularity as well as the surgeon's opinion intra-operatively, and therefore varied considerably, it is difficult to establish the optimum number of ligations.

\section{Conclusion}

HAL-RAR proved to be safe and effective in the present study, showing an acceptable prolapse RR of $11 \%$ after 12 months for this series of high-grade haemorrhoid patients (59\% grade III, $41 \%$ grade IV). Symptom control and patient satisfaction are high, resulting in approximately nine out of ten patients staying symptom-free and satisfied 1 year after surgery. The perioperative complications, which were low in number, were primarily cases of perianal thrombosis and post-operative bleeding. However, to answer the question of the optimum treatment modality ( $\mathrm{CH}, \mathrm{SH}$ and DG-HAL/RAR) for advanced haemorrhoidal disease, a controlled randomized trial would be needed. A multi-centre approach seems mandatory, because no single institution will be able to enrol enough patients or perform all three techniques with adequate experience. However, fully informed consent for such a trial may be problematic. In the absence of such a trial, the nine centres contributing to this study have chosen HAL-RAR as their first-line treatment for high-grade haemorrhoids owing to the perioperative 
benefits, very low number of complications, good symptom control and acceptably low RR.

\section{Conflict of interest}

The authors confirm that they have no form of commercial association, including but not limited to consultancy agreements, stock ownership, equity interests or patent or licensing arrangements, which may represent a conflict of interest in connection with the manuscript.

\section{Open Access}

This article is distributed under the terms of the Creative Commons Attribution License which permits any use, distribution, and reproduction in any medium, provided the original author(s) and the source are credited.

\section{References}

1. Gravie JF, Lehur PA, Huten N, et al. Stapled hemorrhoidopexy versus Milligan-Morgan hemorrhoidectomy: a prospective, randomized, multicenter trial with 2-year postoperative follow up. Ann Surg. 2005;242:29-35.

2. Jayaraman S, Colquhoun PH, Malthaner RA. Stapled versus conventional surgery for hemorrhoids. Cochrane Database Syst Rev. 2006;18(4):CD005393.

3. Ommer A, Wenger FA, Rolfs T, Walz MK. Continence disorders after anal surgery-a relevant problem? Int J Colorectal Dis. 2008;23:1023-31.

4. Sayfan J. Complications of Milligan-Morgan hemorrhoidectomy. Dig Surg. 2001;18:131-3.

5. Palimento D, Picchio M, Attanasio U, Lombardi A, Bambini C, Renda A. Stapled and open hemorrhoidectomy: randomized controlled trial of early results. World J Surg. 2003;27:203-7.

6. Jongen J, Eberstein A, Bock JU, Peleikis HG, Kahlke V. Complications, recurrences, early and late reoperations after stapled haemorrhoidopexy: lessons learned from 1,233 cases. Langenbecks Arch Surg. 2010;395:1049-54.
7. Ravo B. Septic complications after stapled hemorrhoidectomy. J Am Coll Surg. 2005;201:155-6.

8. Morinaga K, Hasuda K, Ikeda T. A novel therapy for internal hemorrhoids: ligation of the hemorrhoidal artery with a newly devised instrument (Moricorn) in conjunction with a Doppler flowmeter. Am J Gastroenterol. 1995;90:610-3.

9. Arnold S, Antonietti E, Rollinger G, Scheyer M. Doppler ultrasound assisted hemorrhoid artery ligation. A new therapy in symptomatic hemorrhoids. Chirurg. 2002;73:269-73.

10. Faucheron JL, Gangner Y. Doppler-guided hemorrhoidal artery ligation for the treatment of symptomatic hemorrhoids: early and three-year follow-up results in 100 consecutive patients. Dis Colon Rectum. 2008;51:945-9.

11. Scheyer M, Antonietti E, Rollinger G, Mall H, Arnold S. Doppler-guided hemorrhoidal artery ligation. Am J Surg. 2006;191:89-93.

12. Scheyer M. Doppler-guided recto-anal repair: a new minimally invasive treatment of hemorrhoidal disease of all grades according to Scheyer and Arnold. Gastroenterol Clin Biol. 2008;32:664.

13. Shao WJ, Li GC, Zhang ZH, Yang BL, Sun GD, Chen YQ. Systematic review and meta-analysis of randomized controlled trials comparing stapled haemorrhoidopexy with conventional haemorrhoidectomy. Br J Surg. 2008;95:147-60.

14. Forrest NP, Mullerat J, Evans C, Middleton SB. Dopplerguided haemorrhoidal artery ligation with recto anal repair: a new technique for the treatment of symptomatic haemorrhoids. Int J Colorectal Dis. 2010;25:1251-6.

15. Jeong WJ, Cho SW, Noh KT, Chung SS. One year follow-up result of Doppler-guided hemorrhoidal artery ligation and recto-anal repair in 97 consecutive patients. J Korean Soc Coloproctol. 2011;27:298-302.

16. Testa A, Torino G, Gioia A. DG-RAR (Doppler-guided rectoanal repair): a new mini invasive technique in the treatment of prolapsed hemorrhoids (grade III-IV): preliminary report. Int Surg. 2010;95:265-9.

17. Walega P, Krokowicz P, Romaniszyn M, et al. Doppler guided haemorrhoidal arterial ligation with recto-analrepair (RAR) for the treatment of advanced haemorrhoidal disease. Colorectal Dis. 2010;12:e326-9. 